\title{
Evaluation of thermal conductivity of the constituent layers in TRISO particles using Raman spectroscopy
}

DOI:

10.1016/j.jeurceramsoc.2017.07.008

\section{Document Version}

Accepted author manuscript

Link to publication record in Manchester Research Explorer

\section{Citation for published version (APA):}

Cao, F., Liu, B., Wang, X., Zhao, X., Guo, F., \& Xiao, P. (2017). Evaluation of thermal conductivity of the constituent layers in TRISO particles using Raman spectroscopy. Journal of the European Ceramic Society. https://doi.org/10.1016/j.jeurceramsoc.2017.07.008

\section{Published in:}

Journal of the European Ceramic Society

\section{Citing this paper}

Please note that where the full-text provided on Manchester Research Explorer is the Author Accepted Manuscript or Proof version this may differ from the final Published version. If citing, it is advised that you check and use the publisher's definitive version.

\section{General rights}

Copyright and moral rights for the publications made accessible in the Research Explorer are retained by the authors and/or other copyright owners and it is a condition of accessing publications that users recognise and abide by the legal requirements associated with these rights.

\section{Takedown policy}

If you believe that this document breaches copyright please refer to the University of Manchester's Takedown Procedures [http://man.ac.uk/04Y6Bo] or contact uml.scholarlycommunications@manchester.ac.uk providing relevant details, so we can investigate your claim.

\section{OPEN ACCESS}




\section{Evaluation of thermal conductivity of the constituent layers in TRISO particles using Raman spectroscopy}

Fangcheng Cao ${ }^{1}$, Bing $\mathrm{Liu}^{2}$, Xin Wang ${ }^{1}$, Xiaofeng Zhao ${ }^{1, *}$, Fangwei Guo ${ }^{1, *}$ and Ping Xiao 3,1

${ }^{1}$ Shanghai Key Laboratory of Advanced High-temperature Materials and Precision Forming, Shanghai Jiao Tong University, Shanghai 200240, China

${ }^{2}$ Institute of Nuclear and New Energy Technology, Tsinghua University, Beijing 100048, China

${ }^{3}$ School of Materials, University of Manchester, Manchester M13 9PL, United Kingdom

\footnotetext{
${ }^{*}$ Corresponding authors.
}

E-mail addresses: xiaofengzhao@sjtu.edu.cn (Xiaofeng Zhao), fwguo2014@sjtu.edu.cn (Fangwei Guo). 


\begin{abstract}
The thermal conductivity of individual layer in the tristructural-isotropic fuel particle was evaluated using Raman spectroscopy. In this method, laser acted simultaneously as an excitation source and a heating source. A three-dimensional point-heating model was developed to estimate the local temperature rise in the probing volume of the laser. The thermal conductivity can be evaluated based on the dependences of the Raman peak position on the temperature and laser power. The calculated thermal conductivities were $8.9 \pm 0.2$ $\mathrm{W} / \mathrm{m} \cdot{ }^{\circ} \mathrm{C}, 13.9 \pm 1.5 \mathrm{~W} / \mathrm{m} \cdot{ }^{\circ} \mathrm{C}$ and $11.9 \pm 0.9 \mathrm{~W} / \mathrm{m} \cdot{ }^{\circ} \mathrm{C}$ for the buffer, the inner and the outer PyC layers, respectively. Contrastly, the thermal conductivity of the $\mathrm{SiC}$ layer was 4.1 $\mathrm{W} / \mathrm{m} \cdot{ }^{\circ} \mathrm{C}$, which is much lower than the reference value, e.g. $168 \mathrm{~W} / \mathrm{m} \cdot{ }^{\circ} \mathrm{C}$ reported by López-Honorato et al. (J. Nucl. Mater. 378(1) 35-39, 2008). The uncertainty of employing Raman spectroscopy to determine thermal conducitvity was discussed.
\end{abstract}

Keywords: Thermal conductivity; Raman spectroscopy; SiC; Fuel particle; Texture. 


\section{Introduction}

High-temperature gas cooled reactor (HTGR) is one of the most promising candidates for the Generation-IV nuclear power system due to its inherently safer design and its capability to provide high power generation efficiency [1]. The superior advantages of HTGR rely on the outstanding performance of its fuel, which is completely different from any currently employed nuclear fuel [2]. This type of fuel, known as tristructural-isotropic (TRISO) particle, is in the form of a small sphere of the fissionable material (e.g. uranium oxide), which is sequentially coated by a porous pyrolytic carbon buffer layer, an inner dense pyrolytic carbon (IPyC) layer, a silicon carbide ( $\mathrm{SiC}$ ) layer, and an outer dense pyrolytic carbon (OPyC) layer [3]. These layers are essential to the safety of HTGR because they are responsible for confining all the fission products inside TRISO particles [2, 3].

TRISO particles need to withstand a working temperature as high as $1400{ }^{\circ} \mathrm{C}$ in the HTGR [4, 5]. The high temperature accelerates degradation and decomposition of the SiC layer [6-8] and migration of the fuel kernel [9], leading to severe damage of the integrity of TRISO particles. Meanwhile, the temperature gradient between the fuel kernel and the outer surface of a TRISO particle, which depends on the thermal conductivity of the individual layer, affects the thermal stress in TRISO particles and the efficiency of the high temperature operating system [1]. Therefore, a systematic investigation on the thermal conductivity of the individual layer in TRISO particles is of importance, since they are main parameters used in modeling the thermal experience and efficiency of TRISO particles.

There are a variety of techniques, such as $3 \omega$ method, heat flow technique and laser-flash technique, to evaluate the thermal conductivity of material. Among them, laser flash technique is the most prevalent approach nowadays, for which the measured sample should have a specified dimension with well-defined thickness. However, these techniques are not 
suitable for TRISO particles because of the multi-layered structure and small spherical shape geometry. López-Honorato et al. reported a time-domain thermoreflectance method to measure the thermal conductivity of each layer in TRISO particle [10]. In this method, a metal film was deposited on the sample as a transducer. The accuracy is limited by the uncertainty in several experimental parameters, such as the metal film thickness and the heat capacity of the sample. In comparison, Raman spectroscopy is a non-destructive, fast and convenient technique to measure the thermal conductivity, in which laser was used as an excitation source as well as a heating source [11]. It was first proposed by Perichon et al., and has attracted considerable interests. This technique is based on two complementary effects: 1) Raman peak shifts with increasing temperature [12], and 2) laser irradiation heats the sample and leads to a local temperature rise, which is related to the thermal conductivity of the sample [13]. Based on the localized heating effect of the laser beam and the temperature dependence of Raman peak position, the thermal conductivity of the material can be estimated. Compared with other techniques, Raman method is nondestructive and less restricted by the sample geometry so it has been extensively used to measure the thermal conductivities of ultrathin films and bulk materials $[11,12,14,15]$. These features are particularly important for analyzing TRISO particles, as the thermal conductivity is very difficult to be measured by other techniques due to its multi-layered structure and small dimension.

The objective of this study is to measure the thermal conductivity of individual layer in TRISO particle using Raman spectroscopy. Measurements were performed on the cross-section of the TRISO particle. Raman spectra were collected at various temperatures and laser powers to establish the peak position-temperature and peak position-power relationships. A 3D model of the localized temperature rise induced by laser irradiation was proposed to determine the thermal conductivity. In addition, as the thermal conductivity of carbon is significantly influenced by the texture $[16,17]$, polarized Raman spectroscopy was 
employed to determine the texture of the PyC layers. The uncertainty of the Raman spectra measurements was also discussed.

\section{Experimental procedure}

\subsection{Sample Preparation}

TRISO particles were fabricated by fluidised bed chemical vapour deposition (FBCVD). Zirconia spheres with a diameter of $\sim 564 \mu \mathrm{m}$ were used as the simulated kernel, which were coated by four successive layers: a buffer layer, a IPyC layer, a SiC layer and a OPyC layer. Deposition conditions and properties of the constitution layers in TRISO particle were listed

in Table 1. To reduce the scattering effects of rough surface to the laser, the TRISO particles samples were embedded in epoxy and ground using conventional metallographic approach with increasingly finer $\mathrm{SiC}$ sandpapers from 600 to 3000 grit. During the grinding procedure, the sample was frequently checked using microscope until to the middle plane (i.e. the maximum diameter) to form a half sphere. The flat surface was further polished using $1 \mu \mathrm{m}$ diamond paste and then $0.03 \mu \mathrm{m}$ alumina suspension, after which the sample was ultrasonically cleaned with alcohol. Acetone was used to dissolve the mounting resin to yield free-standing TRISO hemispherical samples.

Table 1 Deposition conditions and properties of the constitution layers in TRISO particle

\begin{tabular}{cccccc}
\hline Layer & $\begin{array}{c}\text { Deposition } \\
\text { atmosphere }\end{array}$ & $\begin{array}{c}\text { Deposition } \\
\text { temperature }\left({ }^{\circ} \mathrm{C}\right)\end{array}$ & $\begin{array}{c}\text { Thickness } \\
(\mu \mathrm{m})\end{array}$ & $\begin{array}{c}\text { Density } \\
\left(\mathrm{g} / \mathrm{cm}^{3}\right)\end{array}$ & $\begin{array}{c}\text { Optical anisotropy } \\
\text { factor }(\mathrm{OAF})\end{array}$ \\
\hline Buffer & $\mathrm{C}_{2} \mathrm{H}_{2}$ & $1260 \pm 10$ & 95 & 0.88 & N.A. \\
IPyC & $\mathrm{C}_{2} \mathrm{H}_{2} / \mathrm{C}_{3} \mathrm{H}_{6}$ & $1290 \pm 10$ & 40 & 1.93 & 1.01 \\
$\mathrm{SiC}$ & $\mathrm{CH}_{3} \mathrm{SiCl}_{3} / \mathrm{H}_{2}$ & $1560 \pm 10$ & 35 & 3.19 & N.A. \\
$\mathrm{OPyC}$ & $\mathrm{C}_{2} \mathrm{H}_{2} / \mathrm{C}_{3} \mathrm{H}_{6}$ & $1260 \pm 10$ & 40 & 1.96 & 1.02 \\
\hline
\end{tabular}

\subsection{SEM and Raman spectroscopy}

Microstructure of the cross-section of the TRISO particles samples was examined using a 
scanning electron microscope (SEM) (Inspect F50, FEI, USA). Raman spectroscopy of each layer was collected using a confocal Raman microscope (LabRAM HR Evolution, HORIBA Jobin Yvon, France) with a Nd:YAG laser $(532 \mathrm{~nm})$ and 1800 grooves/mm grating. As shown in Figure 1, the sample was placed on the automatic XY mechanical stage under the Raman microscope objective, allowing the sample to be moved in small steps in a well-controlled manner. To achieve a small focused laser spot and high light collection efficiency, the 100x microscope objective (numerical aperture, $\mathrm{NA}=0.9$ ) was used to focus the laser and collected the backscattered light. The depth scan was also performed to characterize the probing depth in the sample, which is a one-dimensional scan in the depth direction ( $z$ direction in Figure 1). During measurements, laser was first focused on the surface of the measured sample and the $z$ position was set to zero. Then the objective lens was moved upward to a negative value of $-10 \mu \mathrm{m}$. During the depth scan, the laser focal plane went from above to below the sample surface in steps of $0.2 \mu \mathrm{m}$ using an automatic stage with the sign of $\mathrm{z}$ from negative to positive and a series of Raman spectra at each step were recorded.

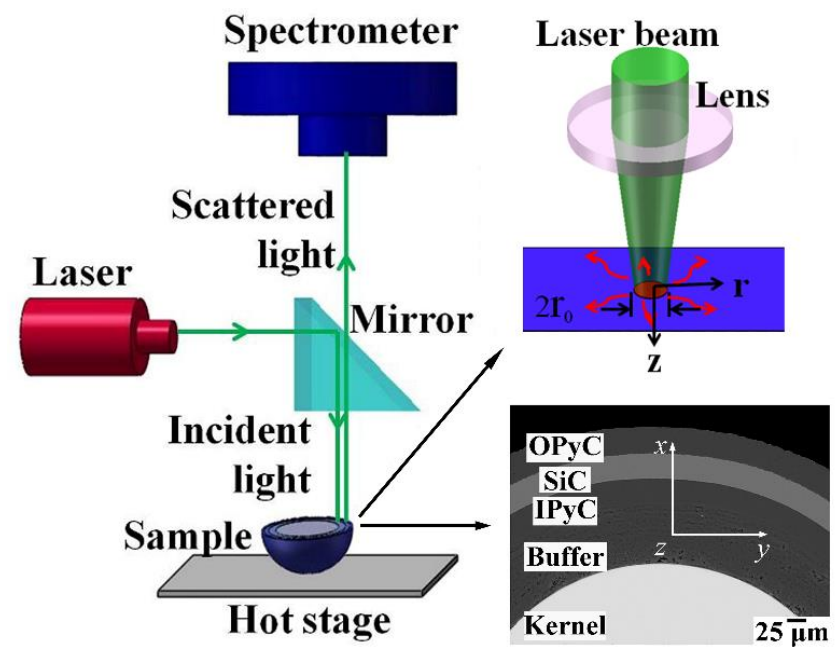

Figure 1 Schematic of the experimental setup for the thermal conductivity measured from the cross-section of the TRISO hemispherical sample using Raman spectroscopy with a hot stage. 
For the temperature dependence measurements, a hot stage (TS1500, Linkam Scientific Instruments, United Kingdom) was used to heat the free-standing TRISO hemispherical sample. Raman spectra were collected from $50{ }^{\circ} \mathrm{C}$ to $250{ }^{\circ} \mathrm{C}$ with an interval of $50{ }^{\circ} \mathrm{C}$. The laser power was maintained below $2 \mathrm{~mW}$ to minimize the laser heating effect. The acquisition time was kept at least $60 \mathrm{~s}$ to ensure a good signal. For the laser power dependence measurements, the power was increased from $1 \mathrm{~mW}$ to $20 \mathrm{~mW}$ at the ambient temperature with other parameters remained the same. Each data was the average of at least ten measurements. The acquired spectra were fitted by mixed Gauss-Lorentzian function using commercial software (Labspec6, Horiba, France) to obtain the Raman peak positions.

\subsection{Polarized Raman spectroscopy}

The coordinates used in the polarized Raman spectroscopy measurement was also shown in Figure 1. The incident and scattered light were in the $z$ direction, the $x$ and $y$ direction were parallel and perpendicular to the deposition plane of the TRISO particle, respectively. The texture of PyC layers was analyzed using polarized Raman spectroscopy with two polarization configurations, namely $\{z(x, x)-z\}$ and $\{z(y, y)-z\}$. The definition of the four-letters expression is called Damen's notation [18], in which the symbols outside the parenthesis show the direction of the incident and scattered light and the symbols in parentheses specify mean the polarization direction of the incident and scattered light, respectively. The polarization configurations were controlled by inserting a half-wave plate and polarizer in the beam path between the sample and the spectrometer. At least ten measurements were carried out for each polarization configuration.

\section{Results}

\subsection{Microstructure of TRISO particle layers}


Figure 2 shows the SEM micrographs of the fractured cross-section of the TRISO particle. The SiC layer consists of a columnar structure with large grains $\sim 1 \mu \mathrm{m}$ in width and $2-5 \mu \mathrm{m}$ in length. The SiC layer is dense, and the density is approximate to the theoretical density (3.2 $\mathrm{g} / \mathrm{cm}^{3}$ ), as presented in Table 1. All the PyC layers are composed of sphere-like carbon particles. Both the IPyC layer and the OPyC layer have large particle size $(\sim 500 \mathrm{~nm}$ in diameter), which is almost twice the size that of the buffer layer. In addition, the IPyC layer and the OPyC layer have relatively high density, while the buffer layer is porous to provide a void volume for gaseous fission products and carbon monoxide [3].
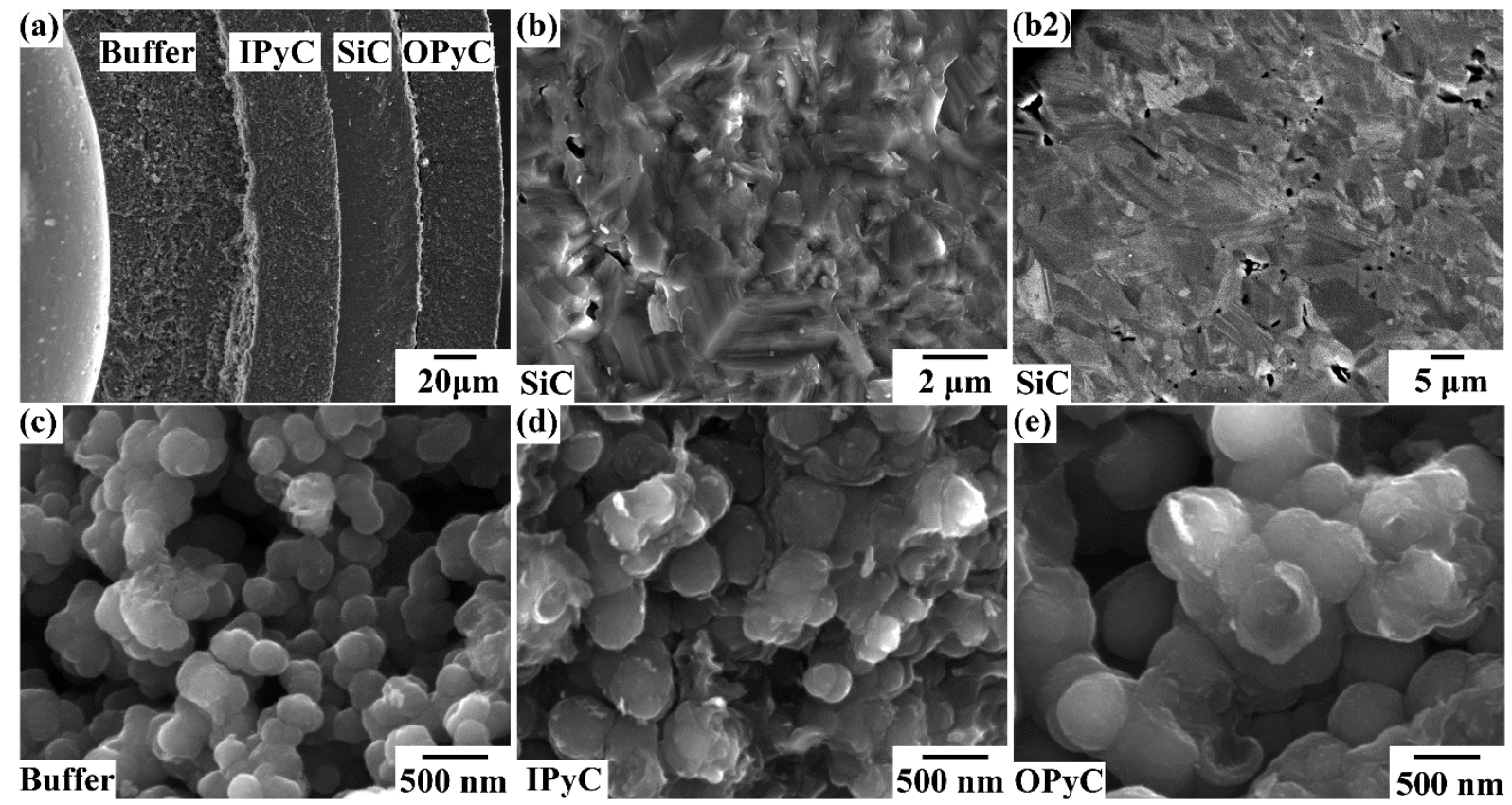

Figure 2 The SEM micrographs of the fractured cross-section of (a) the TRISO particle, (b) the SiC layer with (b2) an inset showing the polished cross-section of the SiC layer, (c) the buffer layer, (d) the IPyC layer and (e) the OPyC layer.

\subsection{Raman spectroscopy of TRISO particle layers}

Figure 3 shows the typcial Raman spectra of each layer measured from the cross-section of the TRISO particle. Raman spectrum of SiC shows two first order peaks at around $796 \mathrm{~cm}^{-1}$ 
(TO peak) and $972 \mathrm{~cm}^{-1}$ (LO peak) with second-order peaks between $1400 \mathrm{~cm}^{-1}$ and 1800 $\mathrm{cm}^{-1}$, which corresponds to stoichiometry $3 \mathrm{C}-\mathrm{SiC}$. A reduction of the symmetry of the LO peak indicates that stacking faults existed within the $\mathrm{SiC}$ layer [18], which may influence the fitting accuracy of the peak. Therefore, the TO peak is chosen to determine the thermal conductivity. Raman spectra of the PyC layers are composed of two first-order peaks at around $1360 \mathrm{~cm}^{-1}$ (D peak) and $1580 \mathrm{~cm}^{-1}$ (G peak) with two second-order peaks between $2700 \mathrm{~cm}^{-1}$ and $2900 \mathrm{~cm}^{-1}$. Compared with the buffer and the IPyC layer, Raman spectrum of the OPyC layer exhibits two broad peaks (e.g. D peak and G peak) due to a large amount of defects in the amorphous carbon structure [18]. It is correlated with the reduction of defects in both the buffer and the IPyC layer after annealing at $1560{ }^{\circ} \mathrm{C}$ during the $\mathrm{SiC}$ deposition process [19]. Likewise, the $G$ peak is used for the calculation of the thermal conductivity instead of D peak, because the D peak could be affected by defects in the carbon structure. Besides, $\mathrm{G}$ peak is more sensitive to temperature.

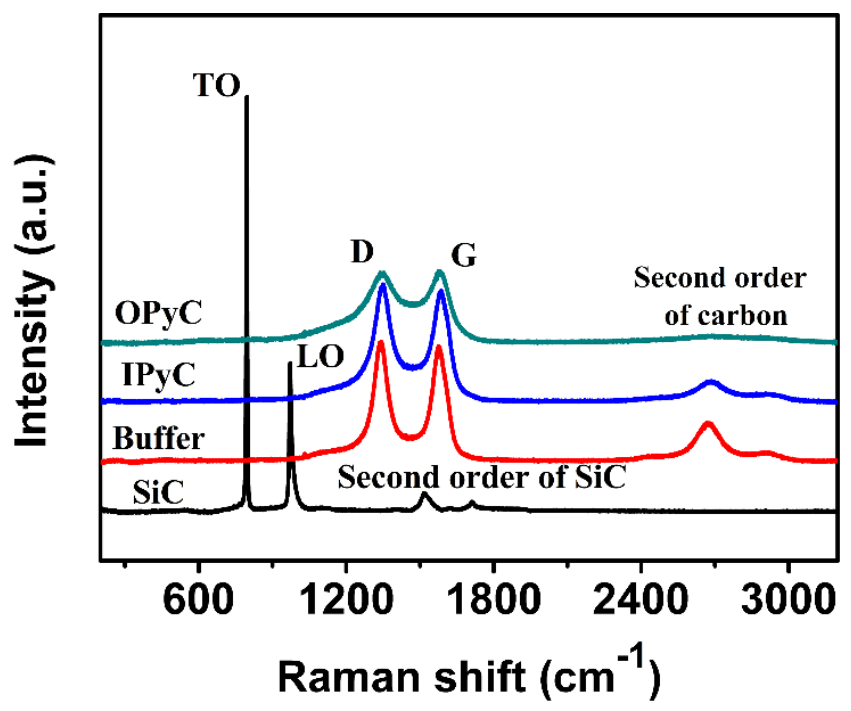

Figure 3 The typical Raman spectra of each layer obtained from the cross-section of the TRISO particle.

It should be noted that Raman spectrum attained from the laser spot is not a true surface 
measurement, instead it is actually averaged over the penetration depth of the excitation beam $[20,21]$. The effective penetration depth $(\delta)$ can be evaluated by [20]:

$$
\delta=\frac{1}{2 \alpha}=\frac{\lambda}{8 \pi k}
$$

where $\alpha$ is the absorption coefficient, $\lambda$ is the wavelength of the incident laser and $k$ is extinction coefficient. For the laser with a wavelength of $\sim 532 \mathrm{~nm}$, the values of $k$ are about 0.017 for amorphous carbon and 0.0013 for $3 \mathrm{C}-\mathrm{SiC}$ [22]. Therefore, the effective penetration depth for the PyC layer and the SiC layer can be estimated to be $\sim 1.25 \mu \mathrm{m}$ and $\sim 16.28 \mu \mathrm{m}$, respectively, which is also confirmed by the depth scan measurement [23]. Figure 4 shows the intensity as a function of defocus distance (the distance away from the focal plane (i.e. the sample surface)). The intensity of all the PyC layers decreases immediately as the laser focus below the surface and converges to zero at position of $\sim 1 \mu \mathrm{m}$, due to their large light absorption. On the contrary, the intensity of the $\mathrm{SiC}$ layer decreases much more slowly with penetration depth and tends to be stable at depth of $\sim 16 \mu \mathrm{m}$. These results agree with the penetration depth values predicted using Equation (1).
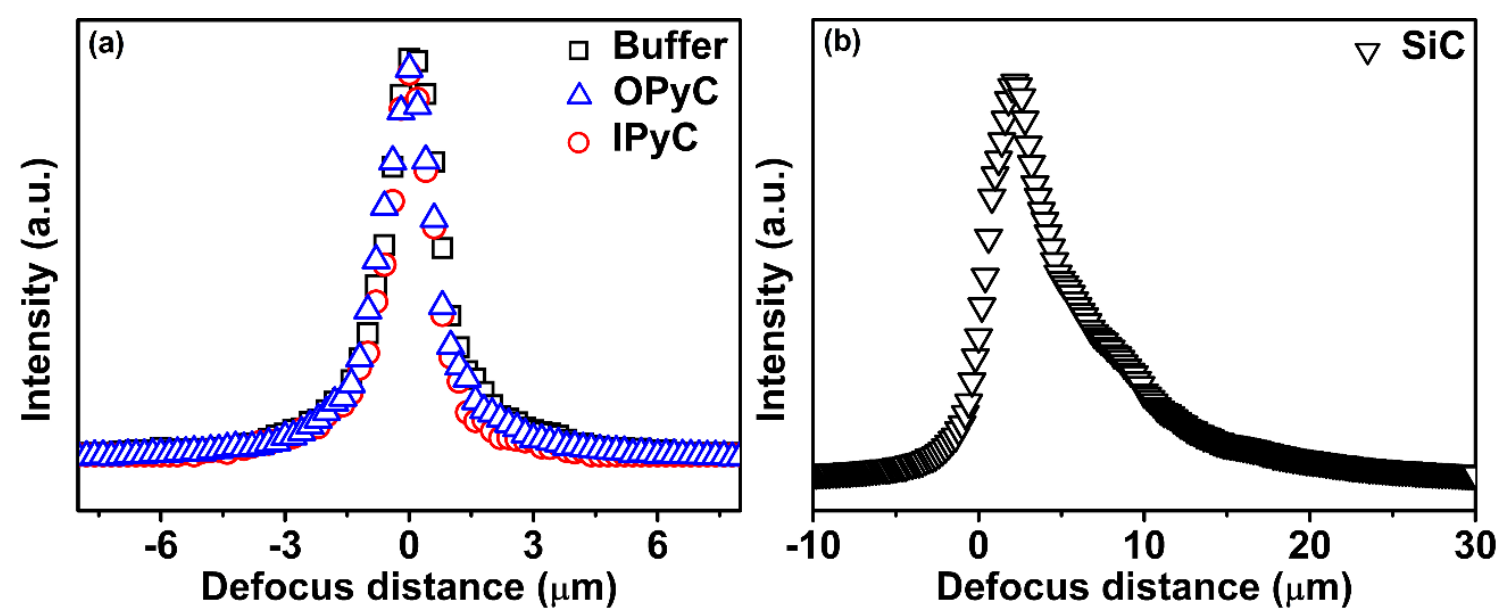

Figure 4 Experimental intensity-through-depth curves for (a) the buffer layer, the IPyC layer, the OPyC layer and (b) the SiC layer. 


\subsection{The texture of the PyC layers}

Thermal conductivity of carbon is significantly influenced by the texture [16, 17]. Therefore, the texture of the PyC layers should be identified. Figure 5 shows the polarized Raman spectra of the buffer layer, the IPyC layer, and the OPyC layer, measured using two polarization configurations of $\{z(x, x)-z\}$ and $\{z(y, y)-z\}$. As the scattering efficiency depends on the relationship between the polarization of the incident and scattered light, and the direction of the crystal planes [24], the intensity ratios at different polarization configurations can be related to the grain orientation. Besides, the polarization ratios $\left(R_{T}\right)$ (i.e. the intensity ratio of $\left.I_{(x, x)} / I_{(y, y)}\right)$ could provided the best correlation with the texture of the PyC layers, which has been previously confirmed by texture measured using the orientation angles from transmission electron microscope [24]. The polarization ratios $\left(R_{T}\right)$ can be calculated by dividing the integrated intensity of the first order peaks between $900 \mathrm{~cm}^{-1}$ and $1850 \mathrm{~cm}^{-1}$ [24]:

$$
R_{T}=\frac{\int_{900}^{1850}(x, x)}{\int_{900}^{1850}(y, y)}
$$

The symbols $x$ and $y$ refer to the polarization direction of the incident light and the scattered light (Figure 1). For the buffer layer, the IPyC layer and the OPyC layer, the polarization ratio $\left(R_{T}\right)$ was $1.16,1.09$ and 1.21 respectively. In the previous study, the polarization ratio $\left(R_{T}\right)$ higher than 1.05 suggested that the PyC layer had low texture [24]. Therefore, all the PyC layers in this study have low texture, which also agrees with the OAF data listed in Table 1. As a result, the effect of texture of the PyC layers on the measurement of the thermal conductivity can be negligible. 


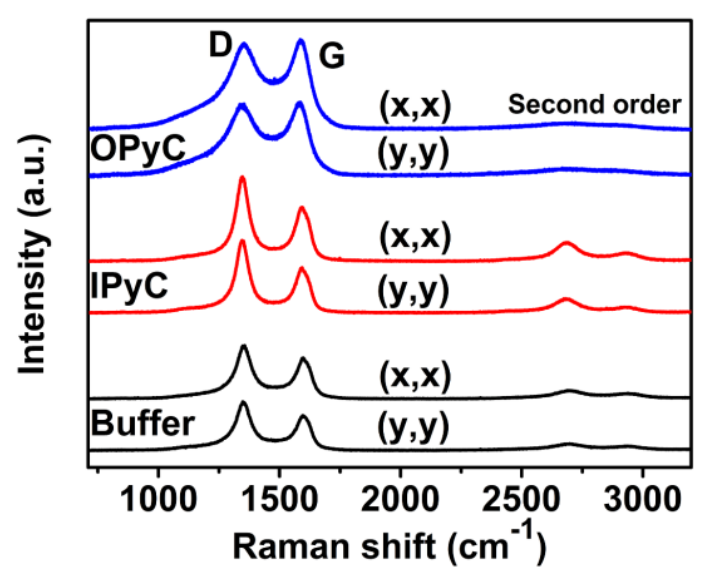

Figure 5 The polarized Raman spectra of the buffer layer, the IPyC layer, and the OPyC layer with $\{z(x, x)-z$ and $\{z(y, y)-z\}$ polarization configurations.

\subsection{Temperature and laser power dependence of Raman spectra}

Figure 6 presents the Raman peak position $(\omega)$ measured at a point in the middle region of each layer from the cross-section of the TRISO particle at different temperatures $(T)$. The Raman peaks shifted to lower frequencies with the increase of the temperature. Each case showed a good linear relationship with strong correlation constant $\left(\mathrm{R}^{2}>0.96\right)$. The temperature coefficient of the SiC layer showed a good consistency with previous report about 3C-SiC $\left(d \omega_{T o} / d T=0.022 \mathrm{~cm}^{-1} /{ }^{\circ} \mathrm{C}\right)$ [25]. Figure 7 presents the Raman peak position $(\omega)$ measured measured at a point in the middle region of each layer from the cross-section of the TRISO particle as a function of the laser power $(P)$. The results show that the Raman peaks monotonically shifted to lower frequencies with the increase of the laser power after a linear fitting. For the range of the laser power used in this study, the Raman peak position change of the PyC layers was more than $18 \mathrm{~cm}^{-1}$, and only $\sim 0.5 \mathrm{~cm}^{-1}$ for the SiC layer. Besides, black spots were observed on the PyC layers after five minutes scan when a $20 \mathrm{~mW}$ laser was used. These results indicate that the heating effect of the laser on the PyC layers is more significant than that on the $\mathrm{SiC}$ layer. Each layer was measured at ten different points for the temperature 
or laser power dependence measurement and their average value was adopted. Both the average temperature coefficients and the average power coefficients obtained from the constitution layers in TRISO particle were summarized in Table 2.
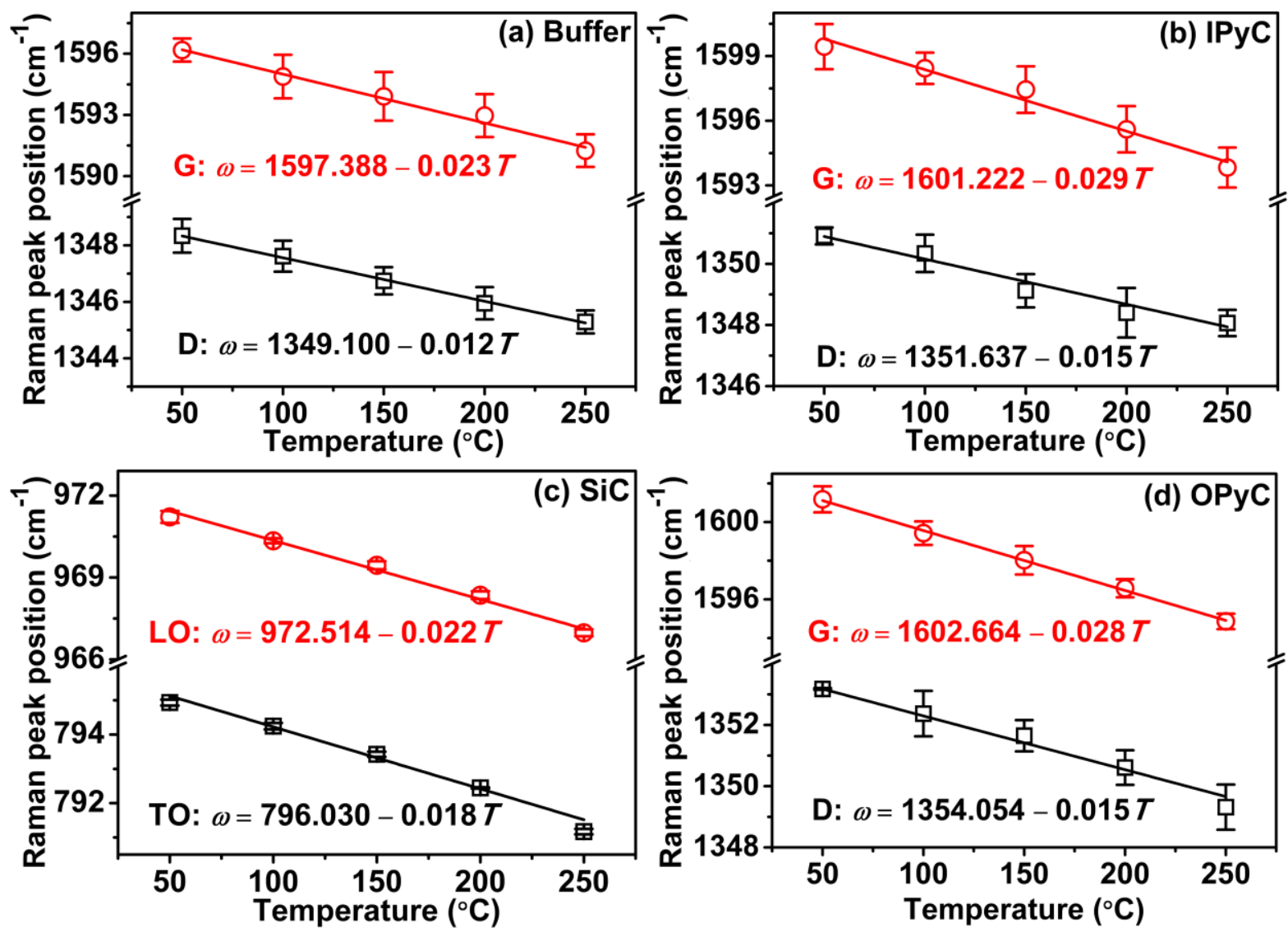

Figure 6 Temperature $(T)$ dependence of the Raman peak position $(\omega)$ measured at a point in the middle region of each layer from the cross-section of the TRISO particle (a) the buffer layer, (b) the IPyC layer, (c) the SiC layer and (d) the OPyC layer, showing good linear fitting correlation constants $\left(\mathrm{R}^{2}>0.96\right)$. 

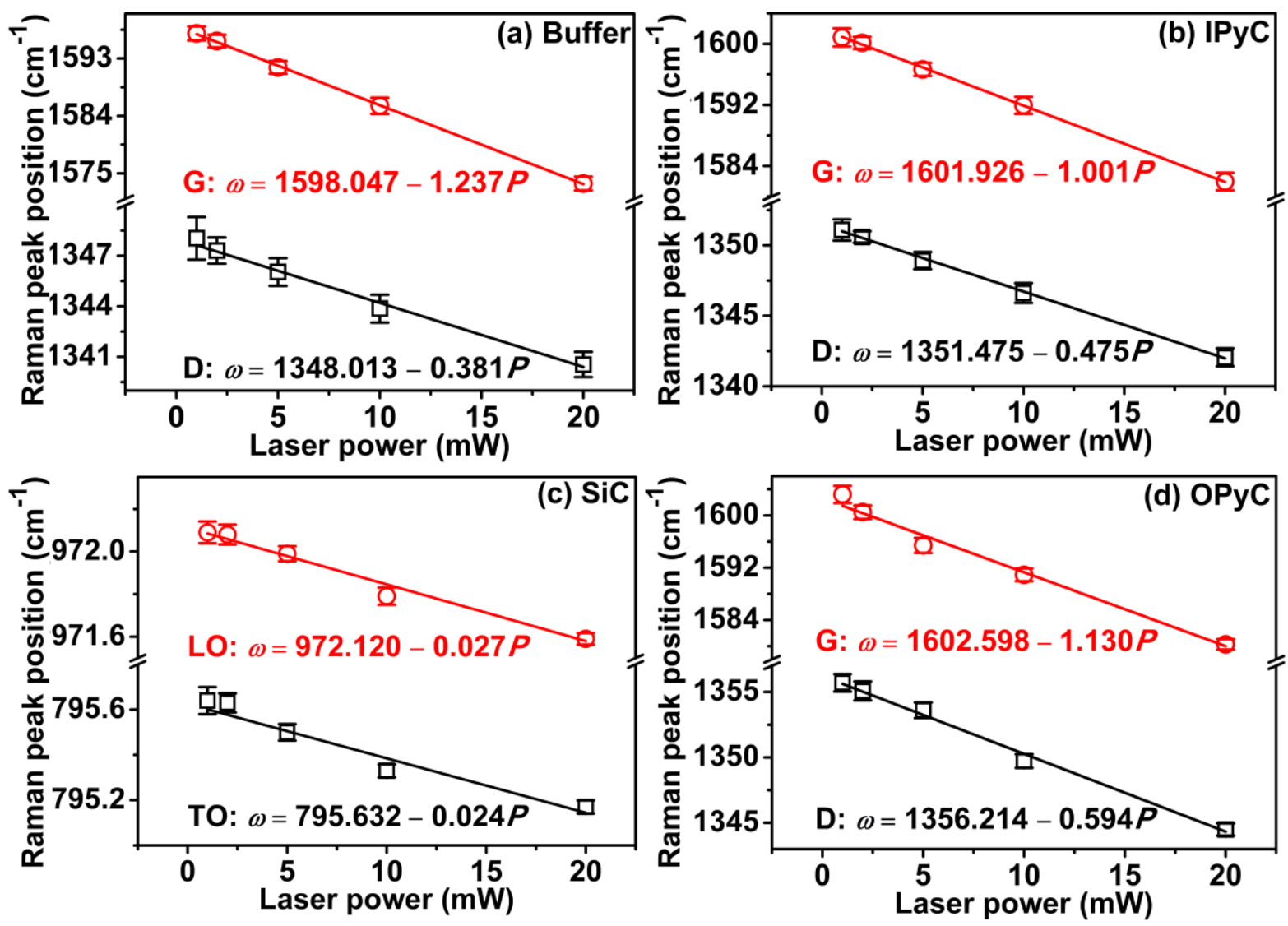

Figure 7 Laser power $(P)$ dependence of the Raman shift $(\omega)$ measured at a point in the middle region of each layer from the cross-section of the TRISO particle (a) the buffer layer,

(b) the IPyC layer, (c) the SiC layer and (d) the OPyC layer, showing good linear fitting correlation constants $\left(\mathrm{R}^{2}>0.94\right)$.

Table 2 The average temperature coefficients amd power coefficients of Raman peak position for the constitution layers in TRISO particle

\begin{tabular}{ccc}
\hline Material & $\begin{array}{c}d \omega / d \bar{T}\left(\mathrm{~cm}^{-1} /{ }^{\circ} \mathrm{C}\right) \\
\mathrm{TO}(\mathrm{SiC}) / \mathrm{G}(\mathrm{PyC})\end{array}$ & $\begin{array}{c}d w / d P\left(\mathrm{~cm}^{-1} / \mathrm{mW}\right) \\
\mathrm{TO}(\mathrm{SiC}) / \mathrm{G}(\mathrm{PyC})\end{array}$ \\
\hline Buffer & $0.023 \pm 0.003$ & $1.237 \pm 0.096$ \\
$\mathrm{IPyC}$ & $0.029 \pm 0.001$ & $1.001 \pm 0.071$ \\
$\mathrm{SiC}$ & $0.018 \pm 0.001$ & $0.024 \pm 0.007$ \\
$\mathrm{OPyC}$ & $0.028 \pm 0.002$ & $1.130 \pm 0.079$ \\
\hline
\end{tabular}

\section{Discussion}

\subsection{Determination of the thermal conductivity}


The localized temperature rise caused by the laser can be deduced from the Raman spectra, according to the temperature dependence of Raman spectra (Figures 6 and 7). And the temperature deduced by the Raman spectra is actually an average temperature of the probing volume of Raman spectra. Meanwhile, the localized temperature distribution induced by the laser could also be directly related to the thermal conductivity of the material by establishing a localized temperature distribution model. Thus, the key procedure to estimate the thermal conductivity is establishing a model of localized temperature rise induced by the laser irradiation in the probing volume of Raman spectra.

Taking the center of the laser beam as the origin point of the cylindrical coordinate system ( $r$,

z) (Figure 1), the beam is usually taken to have a Gaussian transverse intensity profile, as [13]:

$$
I(r)=\frac{P}{\pi r_{0}^{2}} \exp \left(-\frac{r^{2}}{r_{0}^{2}}\right)
$$

where $P$ is the laser power and $r_{0}$ is the laser spot radius. Then the energy absorbed in the material can be presented as [13]:

$$
G(r, z)=\frac{\alpha P}{\pi r_{0}^{2}} \exp (-\alpha z) \exp \left(-\frac{r^{2}}{r_{0}^{2}}\right)
$$

where $\alpha$ is the absorption coefficient. The absorbed laser power is a critical parameter to derive properties of the sample. It is also a key factor to control the localized temperature increase on the sample. In experiments, the incident laser can be absorbed, reflected and transmitted by the sample. Since both the PyC and SiC layers are non-transparent materials, the transmittivity can be neglected and the absorptivity $(A)$ can be deduced as [22]: 


$$
A=1-\frac{(n-1)^{2}+k^{2}}{(n+1)^{2}+k^{2}}
$$

where $n$ is refractive index and $k$ is extinction coefficient. For the laser with a wavelength of $\sim 532 \mathrm{~nm}$, the values of $n$ and $k$ are about 1.98 and 0.017 for amorphous carbon, while 2.67 and 0.0013 for $3 \mathrm{C}-\mathrm{SiC}$ [22]. Then the absorptivity of the PyC layers and the $\mathrm{SiC}$ layer was supposed to be $89 \%$ and $79 \%$, respectively.

To identify the energy absorbed in the material, the radius of the laser spot on the sample surface also needs to be estimated, which could be expressed by [14]:

$$
r_{0}=\frac{\lambda}{\pi N A}
$$

where $\lambda$ is the wavelength of the incident light $(532 \mathrm{~nm}), N A$ is the numerical aperture of the lens (0.9). A spot radius $r_{0}=0.19 \mu \mathrm{m}$ was obtained. Furthermore, the knife-edge method by scanning across a sample with a cleaved edge was performed to calibrate the laser spot size [26]. In this work, a standard sample of Si with a sharp edge was used. Figure 8 shows the Raman intensity of $\mathrm{Si}$ (around $520 \mathrm{~cm}^{-1}$ ) as a function of the moving distance of the laser beam from the cleaved edge. The derivative intensity with respect to the distance $(x)$ could be fitted using a Gaussian function to yield the laser radius, as [14]:

$$
I(x)=I_{0} \exp \left(-2 \frac{x^{2}}{r_{0}^{2}}\right)
$$

where $I_{0}$ is the maximum intensity. Based on Figure 8, the spot radius could be derived. For most of the measurements, an average value of $0.22 \mu \mathrm{m}$ was yielded, which was $16 \%$ greater than that of the diffraction limit predicted using Equation (6). That's, the laser spot size could be affected by focusing distance and the quality of incident beam in real practice. Therefore, the spot size of $0.22 \mu \mathrm{m}$ was used in the following calibration. 


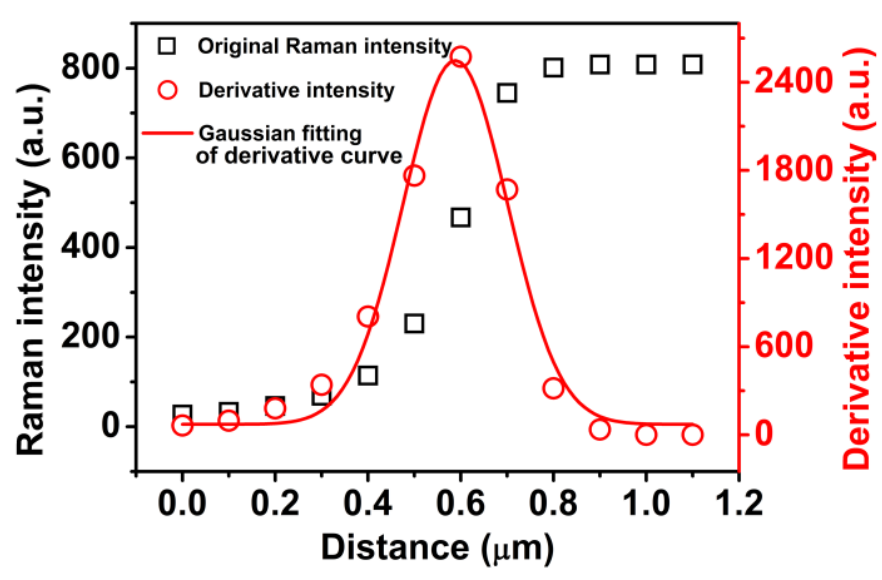

Figure 8 Determination of the laser spot size using the knife-edge method, showing the

Raman intensity of Si and the derivative intensity as a function of the moving distance of the laser beam, respectively.

The energy absorbed in the material induces a local heating effect that triggers a localized temperature rise, which depends on the total power supplied by the laser and the thermal conductivity of the material. The localized temperature at different position within the material has been previously deduced and formulated as [13]:

$$
\begin{aligned}
T(r, z) & =\frac{\alpha A P}{2 \pi K} \int_{0}^{\infty} J_{0}\left(\lambda \frac{r}{r_{0}}\right) \exp \left(-\frac{\lambda^{2}}{4}\right) \times \frac{\alpha r_{0} \exp \left(-\lambda \frac{z}{r_{0}}\right)-\lambda \exp (-\alpha z)}{\left(\alpha r_{0}\right)^{2}-\lambda^{2}} d \lambda \\
T(r, z) & \cong \frac{\alpha A P}{2 \pi K} N(r, z)
\end{aligned}
$$

where $\lambda$ is a variable of the Bessel function of the first kind and zero order $J_{0}(\lambda r), K$ is the thermal conductivity and the $N(r, z)$ is recorded as the result of the numerical integration.

Moreover, the probing volume of Raman spectra can be described as a truncated cone with a finite probing depth. The laser beam radius $r$ is a function of distance $z$ from the focal plane [27]: 


$$
r=r_{0}\left[\left(\frac{z}{c}\right)^{2}+1\right]^{\frac{1}{2}}
$$

where $c$ is the Rayleigh range that represents a characteristic beam size parameter [27]:

$$
\frac{c}{r_{0}}=\cot \left[\sin ^{-1}\left(\frac{N A}{n}\right)\right]
$$

Then the probing volume $\left(V_{c}\right)$ can be expressed as:

$$
V_{c}=\frac{\pi \delta}{3}\left(r_{0}^{2}+r_{0} r^{\prime}+r^{\prime 2}\right)
$$

where $\delta$ is the laser probing depth and $r$ ' is the laser beam radius at a distance of $\delta$ below the sample surface, which can be predicted using Equation (9).

Combining the Equations (8), (9) and (11), the average temperature within the probing volume of Raman spectra can be theoretical expressed by:

$$
\begin{aligned}
& \bar{T}=\frac{1}{V_{c}} \int_{0}^{\delta} \int_{0}^{r} T(r, z) 2 \pi r d r d z \\
& \bar{T}=\frac{\alpha A P}{V_{c} K} \int_{0}^{\delta} \int_{0}^{r}\left[\int_{0}^{\infty} J_{0}\left(\lambda \frac{r}{r_{0}}\right) \exp \left(-\frac{\lambda^{2}}{4}\right) \times \frac{\alpha r_{0} \exp \left(-\lambda \frac{z}{r_{0}}\right)-\lambda \exp (-\alpha z)}{\left(\alpha r_{0}\right)^{2}-\lambda^{2}} d \lambda\right] r d r d z \\
& \bar{T} \cong \frac{\alpha A P}{V_{c} K} \bar{N}(r, z)
\end{aligned}
$$

where $\bar{N}(r, z)$ is the average temperature factor, which is the numerical integration result of the triple integration. In the Equation (12), the laser power was known and the localized temperature rise could be deduced from the Raman spectra based on the temperature dependence of Raman spectra established (Figures 6 and 7). Therefore, the thermal conductivity of the sample can be estimated, as: 


$$
K=\frac{\alpha A P \bar{N}(r, z)}{V_{c} \bar{T}}
$$

To improve the accuracy, we performed a series of measurements with different temperatures and excitation powers to determine the temperature coefficient and laser coefficient of Raman spectra, respectively. Because the Raman peak position exhibited good linear relationship with the temperature and the laser power, the Equation (13) can be rewritten as:

$$
K=\frac{\alpha A \bar{N}(r, z) d P}{V_{c} d \bar{T}}=\frac{\alpha A \bar{N}(r, z)(d \omega / d \bar{T})}{V_{c}(d \omega / d P)}
$$

where $d \omega / d \bar{T}$ is the temperature coefficient and $d \omega / d P$ is the power coefficient derived by the Raman peak position measurement (Figure 6 and 7).

The physical properties for the PyC and SiC layers in TRISO particle were summarized in Table 3. Substituting the relevant values into the Equation (14), the thermal conductivity of the constitution layers in TRISO particle could be calculated and summarized in Table 4, which was compared with that measured using the time-domain thermoreflectance method [10]. It is reasonable that the IPyC layer and OPyC layer had a higher thermal conductivity than the buffer layer with smaller particle size and more pores. The slightly higher thermal conductivity of the IPyC layer than the OPyC layer can be attributed to the reduction of defects in the IPyC layer after annealed at $1560{ }^{\circ} \mathrm{C}$ during the $\mathrm{SiC}$ deposition process. Furthermore, the values for the PyC layers obtained in this study were close to the reported values [10] (Table 4). However, the thermal conductivity of the SiC layer was calculated to be 4.1 W/m. ${ }^{\circ} \mathrm{C}$, which was much smaller than the reported value, e.g. in the range of $80-340$ $\mathrm{W} / \mathrm{m} \cdot{ }^{\circ} \mathrm{C}$ at room temperature for high purity $\mathrm{CVD} \mathrm{SiC}$, using different methods $[3,10]$. Therefore, the accessibility of the measurement of the thermal conductivity of the SiC layer 
using Raman spectroscopy technique need to be further clarified.

Table 3 Summary of the physical properties for the PyC and SiC layers in TRISO particle

\begin{tabular}{ccccc}
\hline Layer & $\begin{array}{c}\text { Absorption } \\
\text { coefficient }\left(\alpha, \mu \mathrm{m}^{-1}\right)\end{array}$ & $\begin{array}{c}\text { Absorptivity } \\
(A)\end{array}$ & $\begin{array}{c}\text { Collection volume } \\
\left(V_{c}, \mu \mathrm{m}^{3}\right)\end{array}$ & $\begin{array}{c}\text { Average } \\
\text { temperature factor } \\
\left(\bar{N}(r, z), \mu \mathrm{m}^{3}\right)\end{array}$ \\
\hline $\mathrm{PyC}$ & 0.40 & 0.89 & 0.86 & 1.16 \\
$\mathrm{SiC}$ & 0.03 & 0.79 & 612.32 & 140.94 \\
\hline
\end{tabular}

Table 4 Summary of thermal conductivities for the constitution layers in TRISO particle

\begin{tabular}{ccccc}
\hline \multirow{2}{*}{ Method } & \multicolumn{4}{c}{ Thermal conductivity $\left(\mathrm{W} / \mathrm{m} \cdot{ }^{\circ} \mathrm{C}\right)$} \\
& Buffer & IPyC & SiC & OPyC \\
\hline $\begin{array}{c}\text { Raman method } \\
\begin{array}{c}\text { Time-domain thermoreflectance } \\
\text { method [10] }\end{array}\end{array}$ & $8.9 \pm 0.2$ & $13.9 \pm 1.5$ & $4.1 \pm 0.6$ & $11.9 \pm 0.9$ \\
$\begin{array}{c}\text { meth } \\
\text { (10.7 }\end{array}$ & 13.5 & 168 & N.A. \\
\hline
\end{tabular}

\subsection{Uncertainty in the thermal conductivity measurement using Raman spectroscopy}

Due to the multi-layered structure and small dimension of TRISO particle, the neighbouring layers might have an impact on the thermal conductivity measurement using the Raman spectroscopy. To evaluate the effects of the neighbour layers, simulations of the temperature distribution in the TRISO particles induced by the laser irradiation were performed. Figure 9a and $9 \mathrm{~b}$ displays a three-dimensional distribution map of $N(r, z)$ at the surface $(z=0)$ according to Equation (8) and the radial distributions of $N(r, z)$ verus $r$ at different depths for the PyC and $\mathrm{SiC}$, respectively. The $N(r, z)$ got the highest value when $z=0$ and $r=0$. With the increase of $z$, the $N(r, z)$ became a much flatter function of $r$. It can also be seen that the heat-affected zone was much larger than the laser probing volume (Equation (11)). In the PyC layers, the temperature was constrained within a region of $|r| \leq 10 \mu \mathrm{m}$ and $z \leq 10 \mu \mathrm{m}$, which is a very small proportion of the PyC layers with a thickness higher than $40 \mu \mathrm{m}$. It can be assumed that measurements of the PyC layers were unaffected by the neighbouring layers. However, for the SiC layer, the temperature distribution covers a larger area $(|r| \leq 100 \mu \mathrm{m}$ and $z \leq 100 \mu \mathrm{m})$, which 
is almost 1000 times of that in the PyC layers. It attributes to the high thermal conductivity of $\mathrm{SiC}$, resulting in a rapid escape of heat produced by the laser irradiation [15]. Thus, the neighbouring PyC layers woud have a strong effect on the measurement of the SiC layer. Meanwhile, substituting the thermal conductivity value $\left(168 \mathrm{~W} / \mathrm{m} \cdot{ }^{\circ} \mathrm{C}\right)$ of the $\mathrm{SiC}$ layer (measured using the time-domain thermoreflectance method [10]) into the Equation (12), the maximum temperature rise in the $\mathrm{SiC}$ layer was calculated to be $2{ }^{\circ} \mathrm{C}$. However, according to the temperature and laser power dependence of Raman spectra for the SiC layer, which were $0.018 \pm 0.001 \mathrm{~cm}^{-1} /{ }^{\circ} \mathrm{C}$ and $0.024 \pm 0.007 \mathrm{~cm}^{-1} / \mathrm{mW}$, respectively, the maximum temperature rise in the $\mathrm{SiC}$ layer could be roughly evaluated to be $24{ }^{\circ} \mathrm{C}$. The maximum temperature rise deduced by the Raman spectra measurement was much larger than that calculated by the theoretical model, which means the neighbouring PyC layers woud constrain the temperature distribution and result in a higher localized temperature rise in the SiC layer. That is, the laser power dependence of Raman spectra would be overestimated, resulting a underestimation of the thermal conductivity of the $\mathrm{SiC}$ layer. In addition, the heating effect in the $\mathrm{SiC}$ induced by the laser was less obvious $\left(\sim 24^{\circ} \mathrm{C}\right)$ and the Raman spectra has a large probing volume in the SiC layer (Table 3), which would result in small shift of Raman peak position and bring in large uncertainty in the temperature measurement using Raman spectroscopy. As a result, it's assumed that the model for the Raman spectroscopy method is not suitable to determine the thermal conductivity of the small dimension SiC layer in TRISO particle. 

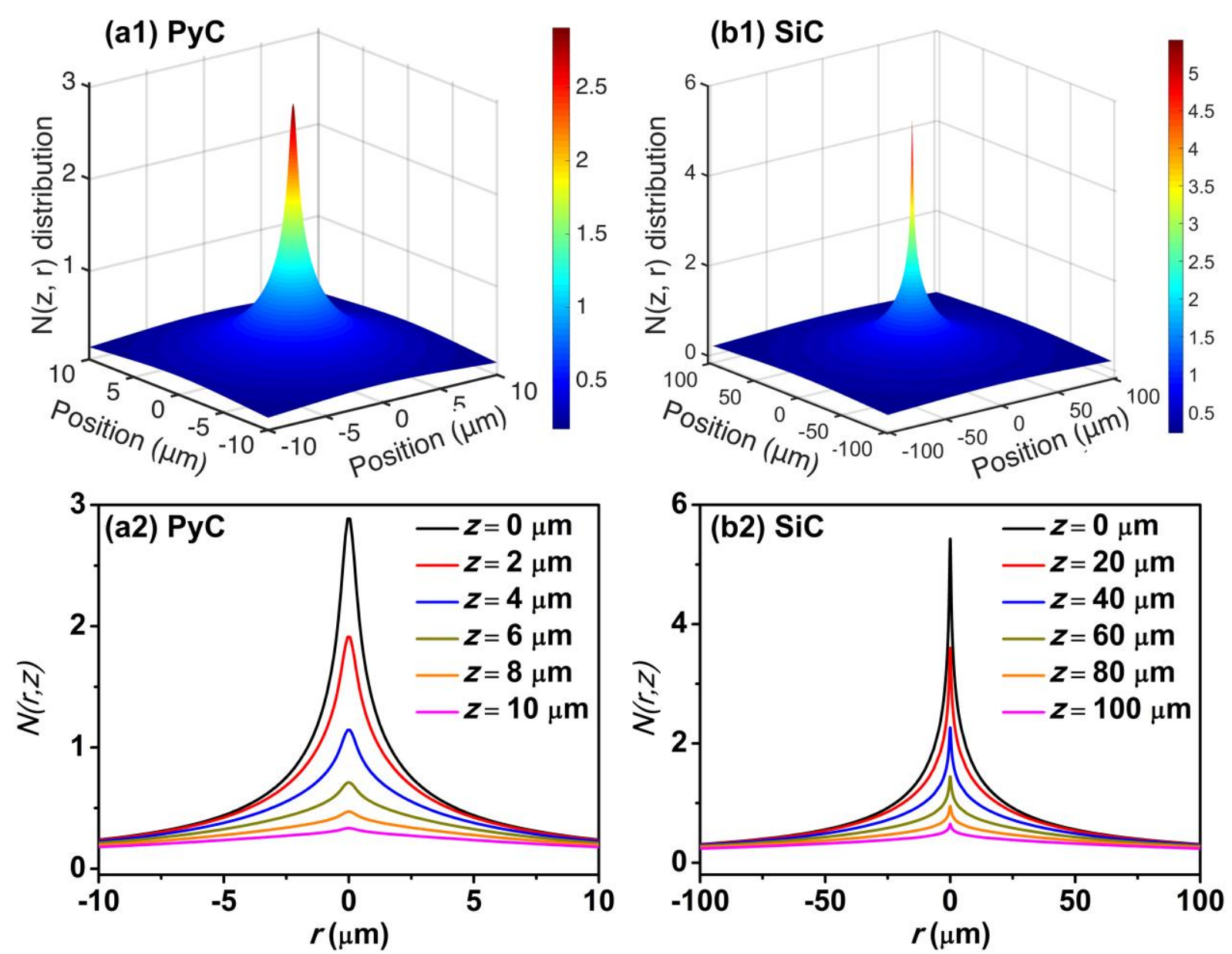

Figure 9 Simulations of three-dimensional distribution map of $N(r, z)$ induced by the laser irradiation at the surface $(z=0)$ and the radial distribution of $N(r, z)$ verus $r$ at different depths for the PyC and SiC, respectively.

On the other hand, when the laser beam irradiates on the sample, the localized temperature rise would also create a compressive stress field in the local region due to the restricted thermal expansion. Previous study reported that the increased temperature led to a shift to lower frequencies and the compressive stress shifted the Raman peak back to higher frequencies, which resulted in a partial compensation [28]. The porous structure of the PyC layers was supposed to release the heating stress to some extent. Besides, the temperature rise in the SiC layer induced by the laser irradiation was low $\left(\sim 24{ }^{\circ} \mathrm{C}\right)$. Therefore, the effect of compressive stress caused by laser heating in each layer in the TRISO particle was negligible. 


\section{Conclusions}

The thermal conductivity of each layer in TRISO particle was evaluated using Raman spectroscopy. The measurements of the temperature and laser power dependence of the Raman peak position were performed, which exhibited good linear relationships. The temperature within the Raman spectra probing volume can be determined by the temperature dependence of the Raman peak position. The model of localized temperature rise induced by the laser irradiation in the probing volume of Raman spectra was established, which can be related to the thermal conductivity.

The effect of low texture of the PyC layers, which was confirmed by the polarized Raman spectroscopy, on the measurement of the thermal conductivity can be negligible. In this study, the temperature distribution in the PyC layers was constrained within a region of $|r| \leq 10 \mu \mathrm{m}$ and $z \leq 10 \mu \mathrm{m}$, which is smaller than the thickness of the PyC layers ( $\geq 40 \mu \mathrm{m})$. It can be assumed that measurements of the PyC layers were unaffected by the neighbouring layers. The effect of compressive stress caused by laser heating on the PyC layers was neglected due to the porosity structure of the PyC layers, which was supposed to release the thermal stress.

The calculated thermal conductivities were $8.9 \pm 0.2 \mathrm{~W} / \mathrm{m} \cdot{ }^{\circ} \mathrm{C}, 13.9 \pm 1.5 \mathrm{~W} / \mathrm{m} \cdot{ }^{\circ} \mathrm{C}$, and $11.9 \pm$ $0.9 \mathrm{~W} / \mathrm{m} \cdot{ }^{\circ} \mathrm{C}$ for the buffer layer, the IPyC layer and the OPyC layer, respectively. Among the PyC layers, the buffer layer has the lowest thermal conductivity due to its lowest density and smallest particle size. The slightly higher thermal conductivity of the IPyC layer than the OPyC layer is attributed to the reduction of defects in the IPyC layer after annealed at 1560 ${ }^{\circ} \mathrm{C}$ during the $\mathrm{SiC}$ deposition process.

The model for the Raman spectroscopy method is not suitable to evaluate the thermal conductivity of the SiC layer in TRISO particle. Because the high thermal conductivity of SiC 
results in a rapid escape of heat produced by the laser irradiation with a large temperature distribution area $(|\mathrm{r}| \leq 100 \mu \mathrm{m}$ and $\mathrm{z} \leq 100 \mu \mathrm{m})$. The neighbouring PyC layers would constrain the temperature distribution in the $\mathrm{SiC}$ layer. Besides, the heating effect in the $\mathrm{SiC}$ induced by the laser was less obvious $\left(\sim 24{ }^{\circ} \mathrm{C}\right)$ and the laser beam has a large probing volume in the $\mathrm{SiC}$ layer, which could generate in large uncertainty in the temperature measurement using Raman spectroscopy.

\section{Acknowledgments}

This research was supported by International Science \& Technology Cooperation Program of China (No. 2016YFE0100700) and the Natural Science Foundation of China (No.51472157, 51402058). The authors are grateful to Dr. Fan Yang from Sheffield University for the proof reading. 


\section{References}

[1]. K. Sawa and S. Ueta, Research and development on HTGR fuel in the HTTR project, Nucl. Eng. Des., 233 [1] (2004) 163-172.

[2]. J. J. Powers and B. D. Wirth, A review of TRISO fuel performance models, J. Nucl. Mater., 405 [1] (2010) 74-82.

[3]. L. L. Snead, T. Nozawa, Y. Katoh, T. S. Byun, S. Kondo, and D. A. Petti, Handbook of SiC properties for fuel performance modeling, J. Nucl. Mater., 371 [1-3] (2007) 329-377.

[4]. I. E. Porter, T. W. Knight, M. C. Dulude, E. Roberts, and J. Hobbs, Design and fabrication of an advanced TRISO fuel with ZrC coating, Nucl. Eng. Des., 259 (2013) 180-186.

[5]. J. T. Maki, D. A. Petti, D. L. Knudson, and G. K. Miller, The challenges associated with high burnup, high temperature and accelerated irradiation for TRISO-coated particle fuel, J. Nucl. Mater., 371 [1] (2007) 270-280.

[6]. G. K. Miller, D. A. Petti, J. T. Maki, and D. L. Knudson, An evaluation of the effects of SiC layer thinning on failure of TRISO-coated fuel particles, J. Nucl. Mater., 355 [1-3] (2006) $150-162$.

[7]. E. López-Honorato, K. Fu, P. J. Meadows, J. Tan, and P. Xiao, Effect of Microstructure on the Resilience of Silicon Carbide to Palladium Attack, J. Am. Ceram. Soc., 93 [12] (2010) 4135-4141.

[8]. H. Zhang, E. López-Honorato, P. Xiao, and V. Sglavo, Effect of Thermal Treatment on 
Microstructure and Fracture Strength of SiC Coatings, J. Am. Ceram. Soc., 96 [5] (2013) $1610-1616$.

[9]. O. Ö. Gülol, Ü. Çolak, and B. Yıldırım, Performance analysis of TRISO coated fuel particles with kernel migration, J. Nucl. Mater., 374 [1] (2008) 168-177.

[10]. E. López-Honorato, C. Chiritescu, P. Xiao, D. G. Cahill, G. Marsh, and T. J. Abram, Thermal conductivity mapping of pyrolytic carbon and silicon carbide coatings on simulated fuel particles by time-domain thermoreflectance, J. Nucl. Mater., 378 [1] (2008) 35-39.

[11]. S. Perichon, V. Lysenko, B. Remaki, D. Barbier, and B. Champagnon, Measurement of porous silicon thermal conductivity by micro-Raman scattering, J. Appl. Phys., 86 [8] (1999) $4700-4702$.

[12]. S. Kouteva-Arguirova, T. Arguirov, D. Wolfframm, and J. Reif, Influence of local heating on micro-Raman spectroscopy of silicon, J. Appl. Phys., 94 [8] (2003) 4946-4949.

[13]. M. Lax, Temperature rise induced by a laser beam, J. Appl. Phys., 48 [9] (1977) $3919-3924$.

[14]. W. Cai, A. L. Moore, Y. Zhu, X. Li, S. Chen, L. Shi, and R. S. Ruoff, Thermal transport in suspended and supported monolayer graphene grown by chemical vapor deposition, Nano Lett., 10 [5] (2010) 1645-1651.

[15]. A. A. Balandin, S. Ghosh, W. Bao, I. Calizo, D. Teweldebrhan, F. Miao, and C. N. Lau, Superior thermal conductivity of single-layer graphene, Nano Lett., 8 [3] (2008) 902-907. 
[16]. T. Kawamura, D. Hori, Y. Kangawa, K. Kakimoto, M. Yoshimura, and Y. Mori, Thermal Conductivity of SiC Calculated by Molecular Dynamics, Japan. J. Appl. Phys., 47 [12] (2008) 8898-8901.

[17]. J. Graebner, S. Jin, G. Kammlott, B. Bacon, L. Seibles, and W. Banholzer, Anisotropic thermal conductivity in chemical vapor deposition diamond, J. Appl. Phys., 71 [11] (1992) $5353-5356$.

[18]. Y. Ward, R. Young, and R. Shatwell, Application of Raman microscopy to the analysis of silicon carbide monofilaments, J. Mater. Sci., 39 [22] (2004) 6781-6790.

[19]. H. Zhang, E. López-Honorato, and P. Xiao, Fluidized bed chemical vapor deposition of pyrolytic carbon-III. Relationship between microstructure and mechanical properties, Carbon, 91 (2015) 346-357.

[20]. H. Harima, Raman scattering characterization on SiC, Microelectron. Eng., 83 [1] (2006) $126-129$.

[21]. M. R. Abel, Thermal metrology of polysilicon MEMS using raman spectroscopy, Master Thesis, Georgia Institute of Technology, 2005.

[22]. E. D. Palik, Handbook of optical constants of solids, Vol. 3. Academic press, New York, U. S., 1998.

[23]. S. Guo and R. I. Todd, Confocal fluorescence microscopy in alumina-based ceramics: Where does the signal come from?, J. Eur. Ceram. Soc., 30 [3] (2010) 641-648. 
[24]. E. López-Honorato, P. J. Meadows, R. A. Shatwell, and P. Xiao, Characterization of the anisotropy of pyrolytic carbon by Raman spectroscopy, Carbon, 48 [3] (2010) 881-890.

[25]. D. Olego and M. Cardona, Temperature dependence of the optical phonons and transverse effective charge in 3C-SiC, Phys. Rev. B, 25 [6] (1982) 3889-3896.

[26]. G. Veshapidze, M. Trachy, M. Shah, and B. DePaola, Reducing the uncertainty in laser beam size measurement with a scanning edge method, Appl. Optics, 45 [32] (2006) $8197-8199$.

[27]. D. M. Lipkin and D. R. Clarke, Sample-probe interactions in spectroscopy: Sampling microscopic property gradients, J. Appl. Phys., 77 [5] (1995) 1855-1863.

[28]. T. Beechem, S. Graham, S. P. Kearney, L. M. Phinney, and J. R. Serrano, Invited Article: Simultaneous mapping of temperature and stress in microdevices using micro-Raman spectroscopy, Rev. Sci. Instrum., 78 [6] (2007) 061301. 